\title{
O DIREITO A CULTURA, AO ESPORTE E AO LAZER COMO ELEMENTOS FUNDANTES DE CIDADANIA: RELAÇÃO DA CONCEPÇÃO DESTE DIREITO NAS REJUPE'S DO BRASIL.
}

\author{
Jorge Antônio Lima de Jesus ${ }^{1}$ \\ Carla Regina da Silva Santos ${ }^{2}$
}

Resumo: Este trabalho aborda o direito à cultura, educação, esporte e lazer como elementos fundantes de cidadania, realizado mediante uma pesquisa bibliográfica com o objetivo de mostrar como uma Rede de Adolescentes e Jovens pelo Direito ao Esporte Seguro e Inclusivo - REJUPE vem propagando e universalizando este direito em várias cidades brasileiras. No desenvolver desta pesquisa, foram utilizados as legislações vigentes e documentos publicados por Meneguzzi e Haslinger (2013) e os autores Candau (2005), Freire (1996) e Santos (1988), além de dialogar com a realidade destes jovens, sua organização e empoderamento dos mesmos como sujeitos de direito. Os estudos trazem à reflexão sobre a cidadania através do direito ao esporte, à educação, ao lazer e à cultura que todo cidadão tem por direito. Logo, a cidadania deve ser entendida como processo contínuo de uma construção coletiva, que segundo a Rede de Adolescentes - REJUPE, oferecer aos adolescentes oportunidades de participação de forma ativa nos debates públicos sobre o direito ao brincar, estudar e praticar esportes significa formar verdadeiros cidadãos para a sociedade.

Palavras-chave: Direito ao Esporte, Cultura e Lazer. Educação. REJUPE. Cidadania.

\begin{abstract}
This work deals with the right to culture, education, sports and leisure as founding elements of citizenship, conducted through a literature search in order to show how a REJUPE - Rede de Adolescentes e Jovens pelo Direito ao Esporte Seguro e Inclusivo is spreading and universalizing this right in several Brazilian cities. In developing this research, current laws and documents were used published Meneguzzi and Haslinger (2013) and authors Candau (2005), Freire (1996) and Santos (1988), as well as dialogue with the reality of these young people, their organization and

\footnotetext{
${ }^{1}$ Autor - Universidade Federal do Pará/UFPA-Belém. Graduando de Licenciatura Plena em Pedagogia. Email: <pedagogojorgelima@gmail.com>. Autor de vários trabalhos no âmbito educacional, destacandose na concepção freireana, tendo coordenado um "Círculo de cultura" no I Fórum de Estudos Leituras de Paulo Freire - Região Norte: Educação Popular em Debate. E-mail: <pedagogojorgelima@gmail.com> ${ }^{2}$ Co-autora - Universidade Federal do Pará/UFPA-Belém. Graduanda de Licenciatura Plena em Pedagogia. E-mail. >carlinhaufpa@gmail.com>. Servidora pública na Superintendência do Sistema Penal/PA. Membro voluntário do Grupo de Pesquisa em Sociologia da Educação na Amazônia: Perspicilli. Não conta com financiamento.
}

Revista PET Interdisciplinar e Programa Conexões/UFPA On-line. Vol. 01 - 2016. Página 63 
empowering them as subjects of rights. Studies betray reflection on citizenship right through to sport, education, leisure and culture that every citizen has the right. Therefore, citizenship should be understood as a continuous process of collective construction, which according to Rejupe, provide adolescents opportunities to participate actively in the public debate on the right to play, study and play sports means to form true citizens for the society.

Keywords: Right to Sport, Culture and Leisure. Education. REJUPE. Citizenship.

\section{Introdução}

O presente trabalho tem como temática abordar o direito a cultura, educação, esporte e lazer como elementos fundantes de cidadania, realizado mediante uma pesquisa no intuito de mostrar como uma Rede de Adolescentes e Jovens pelo Direito ao Esporte Seguro e Inclusivo - REJUPE ${ }^{3}$ vem propagando e universalizando este direito em várias cidades brasileiras.

A Rede de Adolescentes REJUPE é um espaço de participação e integração formado por adolescentes brasileiros com a finalidade de proporcionar a troca de experiências entre adolescentes, jovens e grupos de participação cidadã de diversas regiões do país para consolidar ações de defesa e promoção do direito a esporte seguro e inclusivo, para todas as crianças e adolescentes do Brasil, assim como iniciativas que incidam diretamente no planejamento e construção de um legado social positivo para os megaeventos esportivos desta década. Com essa motivação, a REJUPE se articula e mobiliza esforços dirigidos aos objetivos de incentivar os adolescentes para a defesa e promoção deste direito; sensibilizar e mobilizar acerca das discussões pelo direito ao esporte e ao lazer; estimular a representatividade dos adolescentes na elaboração de políticas públicas sobre este direito e empoderar os adolescentes brasileiros para que eles sejam ouvidos pela sociedade.

\section{Objetivos}

O objetivo do deste trabalho é a conscientização e reflexão acerca do direito ao esporte, lazer e cultura para às crianças e adolescentes. $\mathrm{O}$ documento "Cultura, Lazer e

\footnotetext{
${ }^{3}$ REJUPE: Rede de Adolescentes e Jovens pelo Direito ao Esporte Seguro e Inclusivo criada a partir do encontro realizado nos dias 6 e 7 de abril de 2011, no Rio de janeiro, Brasil, do qual participaram 202 adolescentes de diversas redes e grupos de participação e protagonismo procedentes de 11 estados brasileiros. Com base nos debates e nas necessidades apontadas pelos adolescentes para a garantia do direito ao esporte e com o apoio estratégico do UNICEF. Disponível em: $<$ http://www.rejupe.org.br/sobre-a-rejupe>
} 
Esporte como Elementos Fundadores de Cidadania" de Meneguzzi e Haslinger (2013) vem nos fazer refletir sobre a cidadania por meio do direito ao esporte, ao lazer e à cultura que todo cidadão tem por direito, pois ser cidadão é todo aquele que participa, colabora e argumenta sobre as bases do direito, ou seja, é um agente atuante que exerce seus direitos e deveres. Ser cidadão implica em não se deixar oprimir nem subjugar, mas enfrentar o desafio para defender e exercer seus direitos. Cidadania é a tomada de consciência de seus direitos, tendo como contrapartida a realização dos deveres. Isso implica no efetivo exercício dos direitos civis, políticos e socioeconômicos, bem como na participação e contribuição para o bem-estar da sociedade. A cidadania deve ser entendida como processo contínuo, uma construção coletiva, significando a concretização dos direitos humanos.

\section{Metodologia}

No desenvolvimento da pesquisa foram utilizados literaturas e documentos referentes aos Direitos Humanos, a Constituição Federal Brasileira, Estatuto e Criação do REJUPE. Além das aulas práticas da disciplina "Estado, Sociedade e Educação em Direitos Humanos", assim como o "Caderno de Educação Popular e Direitos Humanos" (MENEGUZZI E HASLINGER, 2013), como também as ações afirmativas e de negação deste direito em nosso país, pesquisadas nos sítios destes assuntos na internet e nas literaturas já publicadas sobre o tema dialogando com os autores Candau (2005), Freire (1996) e Santos (1988).

\section{Resultados e discussão}

O direito à cultura, esporte e lazer é direito humano porque a necessidade de se expressar, manifestar pensamentos e valores é intrínseca à condição humana. Vivemos tempos onde os espaços culturais para manifestação são escassos, onde a cultura se mercantilizou e somente tem acesso quem pode pagar por um ingresso de cinema e teatro. Porém, há toda uma dinâmica cultural onde diversos grupos sociais, a partir das suas próprias percepções e referenciais, criam cidadania cultural.

Considerando que, na Declaração Universal dos Direitos Humanos, os países signatários da Organização das Nações Unidas - ONU proclamam a dignidade e o valor da pessoa humana, na igualdade de direitos e se declaram favoráveis ao progresso social e à instauração de melhores condições de vida dentro de uma liberdade mais ampla, A REJUPE assume com o objetivo de contextualizar o direito ao esporte, lazer e cultura 
nos trazendo experiências na Educação Popular e dialogam sobre esse direito humano fundamental para as crianças e jovens adolescentes. No entanto, os fundamentos para a garantia dos direitos fundamentais da criança e do adolescente enquanto pessoa humana tem sua origem na Declaração Universal dos Direitos Humanos (1948), sendo fortalecidos por subsequentes documentos legais decorrentes da Declaração Universal dos Direitos da Criança e do Adolescente (1959) e outros conclaves de igual importância que se sucedem após o advento do Estatuto da Criança e do Adolescente.

Os Direitos Sociais são conquistas dos movimentos sociais ao longo dos séculos, e, atualmente, são reconhecidos no âmbito internacional. Em nossa Constituição Federal de 1988 aponta que o lazer é considerado dever do Estado e garantido, de forma ampla, na constituição Federal de 1988, que menciona o direito ao lazer, de forma clara entre os direitos sociais no art. $6^{\circ}$, embora não de forma específica, o documento analisado nos revela que este direito é fundante da cidadania compreendida como apropriação da realidade para nela atuar com dignidade, participando em favor de sua emancipação como verdadeiro cidadão de direitos e de fato.

Nessa perspectiva, os direitos de segunda geração, assim chamados os direitos humanos sociais, nascem da necessidade de obrigar o Estado a assumir uma postura intervencionista e promotora da igualdade entre os cidadãos - em oposição à concepção negativa de Estado Liberal que prestigia exclusivamente os direitos individuais de liberdade - de forma a fornecer certo número de serviços para diminuir as desigualdades econômicas e sociais, permitir a participação de todos no bem-estar social e na divisão das riquezas, e promover a justiça social (TOSI, 2005, p.118). Dessa forma que, conforme ensina ORTIZ (2004, p.7), emerge o Estado Social, um agente promotor, dotado de um poder único capaz de atenuar as diferenças sociais, de melhorar a qualidade de vida dos indivíduos e de promover o desenvolvimento da sociedade mediante a adoção de políticas públicas de promoção social e de acesso a garantias básicas como o direito a cultura, ao esporte e ao lazer.

Ao colocar este direito ao Esporte, Lazer e Cultura a outros direitos sociais e individuais, como dever do Estado; na seção III do Cap. III, do Título VIII da Constituição Federal, quando explícita o desporto, que pode ser relacionado ao direito a educação, cultura e lazer; por fim, no art. 217, $\S 3^{\circ}$, ao explicitar o dever do Poder Público em incentivar o lazer como forma de promoção social. Os Parâmetros Curriculares Nacionais da Educação Brasileira, por sua vez, referem-se à importância do lazer no espaço pedagógico. 
O lazer e a disponibilidade de espaços para atividades lúdicas e esportivas são necessidades básicas e, por isso, direitos do cidadão. Os alunos podem compreender que os esportes e as demais atividades corporais não devem ser privilégios apenas dos esportistas ou das pessoas em condições de pagar por academias e clubes. Dar valor a essas atividades e reivindicar o acesso a elas para todos é um posicionamento que pode ser adotado a partir dos conhecimentos adquiridos nas aulas de Educação Física. (Parâmetros Curriculares Nacionais, vol. 03 Educação Física. 2003).

A concepção deste direito está fundamentada também em nossa Constituição Federal (1988), no art. 6. "São direitos sociais a educação, a saúde, a alimentação, o trabalho, a moradia, o lazer, a segurança, a previdência social, a proteção à maternidade e à infância, a assistência aos desamparados, na forma desta Constituição." (Redação dada pela Emenda Constitucional $n^{\circ}$ 64, de 2010); em contrapartida, conforme o documento analisado, nos afirma que desde 1990 quando foi sancionado o Estatuto da Criança e do Adolescente (ECA) e que vem apontando especificamente o direito ao lazer, ao esporte e a cultura como direitos humanos; pois a necessidade de se expressar, manifestar pensamentos e valores é intrínseco à condição humana. No Estatuto da Criança e do Adolescente (ECA) refere-se em seu Art. $4^{\circ}$ que:

É dever da família, da comunidade, da sociedade em geral e do poder público assegurar, com absoluta prioridade, a efetivação dos direitos referentes à vida, à saúde, à alimentação, à educação, ao esporte, ao lazer, à profissionalização, à cultura, à dignidade, ao respeito, à liberdade e à convivência familiar e comunitária. (BRASIL. Lei no 8.069, de 13 de julho de 1990, 1990).

A liberdade deste direito se constitui necessidade de lazer e educação próprios a

todos os seres humanos. À luz destas perspectivas é de fundamental importância entender que o esporte, o lazer e a cultura como direitos sociais assentados na Educação em Direitos Humanos, cuja efetivação como pauta a reflexão das autoras não é tarefa somente do Estado, como já foi exemplificado, pois a implementação desses direitos é, também, missão de toda sociedade civil, e a luta pela efetivação de todo e qualquer direito social é que irá concretizar o referido direito, como o direito ao esporte, ao lazer e a cultura no cotidiano das pessoas, e que determinarão sua legitimação em determinada sociedade.

\section{Conclusão}

Diante do exposto pode se afirmar que é dever do Estado garantir por intermédio de políticas públicas a efetivação deste direito, e cabem aos pais e à sociedade em geral 
garantir que seus filhos vivam a infância com muitas brincadeiras, que pratiquem esportes dentro de suas possibilidades no intuito de fundamentar a base humana para uma adolescência e vida adulta saudável, formando indivíduos responsáveis. Conhecemos as dificuldades dos ambientes escolares, notadamente públicos e periféricos, de serem visualizados como potenciais espaços de lazer, porém muitos destes espaços de ação educativa sofrem as consequências de teorias pedagógicas não críticas, eivadas por concepções mercadológicas de lazer e educação, que dão pouca visibilidade a essas possibilidades.

Relacionado este direito social às ações da Rede de Adolescentes e Jovens pelo Direito ao Esporte e Inclusivo, quando analisadas historicamente, observamos que há uma memória da mesma que reivindica políticas públicas específicas a respeito desta questão, e por meio destas ações afirmativas que a REJUPE pode criar um diálogo constante com a comunidade, formando sujeitos que tenham consciência de seus direitos e de seu papel de cidadão. Um dos educadores que mais contribuíram com esse conceito foi Paulo Freire, importante pedagogo brasileiro que desenvolveu trabalhos voltados para a educação como ferramenta emancipadora do indivíduo.

Os direitos sociais "nasceram abraçados ao princípio da igualdade" e sãos os que mais se aproximam do princípio da dignidade da pessoa humana e da cidadania, pois visam a reduzir as desigualdades entre as pessoas, proporcionando aos indivíduos melhores condições de vida; conclui-se que a efetivação desses direitos sociais é indispensável para o exercício de outros direitos e liberdades fundamentais a todo ser humano. "Construir, reconstruir, constatar para mudar, o que não se faz sem abertura ao risco e à aventura do espirito". (FREIRE, 1996.)

\section{Referências}

BETTO, Frei. CIDADANIA. Educação em Direitos Humanos. Frei Betto. Disponível em: <http://www.dhnet.org.br/educar/redeedh/bib/betto.htm> Acesso 17/11/2015.

BRASIL. Comitê Nacional de Educação em Direitos Humanos. Programa Nacional de Educação em Direitos Humanos. Brasília: SEDH/MEC/Ministério de Justiça/UNESCO, 2006.

Constituição da República Federativa do Brasil de 1988. Disponível em: <http://www.planalto.gov.br/ccivil_03/constituicao/constituicao.htm>Acesso em: 15 mar.2015. 
. Lei no 8.069, de 13 de julho de 1990. Disponível em:

<http://www.planalto.gov.br/ccivil_03/Leis/18069.htm> Acesso em: 19/11/2015.

CANDAU, Vera Maria. Educação em direitos humanos: principais desafios. Rio de Janeiro: 2005.

CARBONARI. Paulo César. Educação em direitos humanos.In.: Por uma nova pedagogia.Paulo César Carbonari. Disponível em:

<http://www.dhnet.org.br/direitos/militantes/carbonari/textos.htm> Acesso 20/11/2015.

UNIDAS, Organização das Nações Unidas. Declaração Universal dos Direitos

Humanos. Disponível em:

<http://www.dhnet.org.br/direitos/deconu/textos/integra.htm> Acesso em: 19/11/2015.

FREIRE, Paulo. Pedagogia da autonomia. São Paulo: Paz e Terra, 1996.

MENEGUZZI, Fabiele Z; HASLINGER, Evelin. Cultura, lazer e esporte como elementos fundadores de cidadania. In: Caderno de Educação Popular e Direitos Humanos. Projeto E-DHESCA. Conectando Redes e Saberes. SG/PR - SDH/PR CAMP. BRASIL. 2013.

ORTIZ, Maria Elena Rodriguez. Apresentação. In: Justiça Social: uma questão de direito. DP\&A Editora, Rio de Janeiro, 2004.

REJUPE - Rede de Adolescentes e Jovens pelo Direito ao Esporte e Inclusivo.

Disponível em: http://www.rejupe.org.br/Acesso 28.10.2015.

SANTOS, Robson. Afinal, o que são Direitos Humanos? Revista Sociologia - ciência \& vida $n^{\circ}$ 05. Jan. 1988.

TOSI, Giuseppe. História conceitual dos direitos humanos. In: TOSI, Giuseppe (org.). Direitos Humanos: História, Teoria e Prática. Editora Universitária UFPB, João Pessoa, 2005.

\section{Agradecimentos.}

À Professora Dra. Émina Santos, do curso de Licenciatura em Pedagogia da Universidade Federal do Pará pela dedicação à Educação em Direitos Humanos e pela luta em prol da militância para a efetivação dos Direitos Humanos na universidade, na vida, na escola, na sociedade, em nossa educação de fato e que muito contribuiu para a construção deste trabalho com a disciplina eletiva "Estado. Sociedade. Educação em Direitos Humanos". 